\title{
PRINCÍPIOS PARA A INSTITUCIONALIZAÇÃO DA AMBIENTALIZAÇÃO CURRICULAR NA EDUCAÇÃO SUPERIOR: DA SENSIBILIZAÇÃO À ECOCIDADANIA SOCIOAMBIENTAL
}

\author{
Junior Cesar Mota ${ }^{1}$; Dione lara Silveira Kitzmann²
}

\section{RESUMO}

Estudos acerca do processo de Ambientalização Curricular na Educação Superior têm se potencializado nas últimas décadas. No entanto, ainda se carece de pesquisas que busquem institucionalizar tal processo de forma efetiva nos currículos. Ao buscar preencher esta lacuna, este artigo, oriundo de uma Proposta Téorico-Metodológica para a Ambientalização Curricular que está sendo desenvolvida e aplicada em uma pesquisa de doutorado no Programa de Pós-Graduação em Educação Ambiental - PPGEA, da Universidade Federal do Rio Grande - FURG, apresenta resumidamente, oito Princípios basilares à institucionalização deste processo nas Instituições de Ensino Superior, construídos a partir das Diretrizes Curriculares para Educação Ambiental no Brasil: 1) Sensibilização estético-ambiental; 2) Complexidade bioecossistêmica; 3) Globalização e Pertencimento ao lugar; 4) Sustentabilidade; 5) Justiça socioambiental; 6) Mudanças do Clima; 7) Pensamento crítico-reflexivo; e 8) Ética e Ecocidadania.

Palavras-chave: Educação Ambiental; Ambientalização Curricular; Educação Superior.

\section{PRINCIPLES FOR THE INSTITUTIONALIZATION OF CURRICULAR ENVIRONMENTALIZATION IN HIGHER EDUCATION: FROM SENSITIZATION TO SOCIOENVIRONMENTAL ECOCITIZENSHIP}

\begin{abstract}
Studies about the process of Curricular Environmentalization in Higher Education have been increasing in recent decades. However, there is still a lack of research that seeks to institutionalize this process effectively in curricula. In seeking to fill this gap, this article, which comes from a theoreticalmethodological proposal for curricular environment, which is being developed and applied in a doctoral research, in the Postgraduate Program in Environmental Education - PPGEE, Federal University of Rio Grande - FURG,

1 Mestre em Educação. Doutorando no Programa de Pós-Graduação em Educação Ambiental - PPGEA. Universidade Federal do Rio Grande - FURG. Bolsista da CAPES. E-mail: juniormota@furg.br.

2 Doutora e Mestra em Educação Ambiental. Universidade Federal do Rio Grande - FURG. Email: docdione@furg.br.
\end{abstract}


shows briefly, eight basic Principles to the institutionalization of this process in Higher Education Institutions, built from Curricular Guidelines for Environmental Education in Brazil: 1) Aesthetic-environmental awareness; 2) Bioecossistic complexity; 3) Globalization and Belonging to the place; 4) Sustainability; 5) Social and environmental justice; 6) Climate Change; 7) Critical-reflexive thinking; and 8) Ethics and Eco-citizenship.

Keywords: Environmental Education; Curricular Environmentalization; Higher Education.

\section{Ambientalização Curricular na Educação Superior: os oito Princípios para sua institucionalização}

O processo de Ambientalização Curricular (AC) tem se potencializado nas últimas décadas incluindo a reorganização do currículo que direciona a aspectos integradores do campo científico da Educação Ambiental (EA), transcendendo a ideia de esverdeamento ou maquiagem curricular. Ou seja, incorporar transversalmente os princípios e objetivos da EA e da sustentabilidade é imprescindível para que a ambientalização se implemente e se potencialize na prática. Interligado a isto, existem outros fatores de cunho curricular (tais como participação democrática, diálogo de saberes, construção coletiva, dentre outros) que precisam ser repensados para que o modelo moderno seja desconstruído na práxis.

Corroborando tais premissas, a Rede de Ambientalização Curricular do Ensino Superior - Rede ACES, elaborou um dos primeiros conceitos, mostrando que a AC é um "processo contínuo de produção cultural voltado à formação de profissionais comprometidos com a busca permanente de melhores relações possíveis entre a sociedade e a natureza [...]" (JUNYENT, GELI \& ARBAT, 2003, p. 21). No entanto, por mais significativa que a operacionalização e a institucionalização de tal processo possa ser para as Instituições de Ensino Superior (IES), ainda se carece de estudos que explicitem como isto se traduz na parte burocrática e formativa curricular. Foi a partir dessa angústia e dessas interlocuções de valores, que este trabalho, oriundo de uma tese em andamento no Programa de Pós-Graduação em Educação Ambiental, da Universidade Federal do Rio Grande, objetiva apresentar oito Princípios basilares para essa concretização nas IES. Para isto, recorreu-se às Diretrizes Curriculares para Educação Ambiental do Brasil DCNEA (BRASIL, 2012), considerando que estas servem como um guia 
norteador de fundamentos a serem seguidos.

Referente ao currículo, as DCNEA trazem uma seção específica sobre organização curricular. No Art. 16, um dos que compõem essa seção, é previsto como pode ocorrer a integração dos conhecimentos da temática ambiental na Educação Básica e na Educação Superior. Tal ação pode acontecer por meio da transversalidade dos temas relacionados com o meio ambiente e a sustentabilidade; como conteúdo dos componentes já constantes nos currículos; ou por combinação desses dois meios. Em um parágrafo único, as Diretrizes denotam autonomia para que as IES encontrem outras formas dessa integração acontecer, considerando a natureza dos cursos.

Já no Art. 17, que também compõe a seção referente à organização curricular, são apontados os deveres do planejamento curricular e da gestão institucional perante os valores da sustentabilidade e da EA. Dentre eles, é ressaltado o estímulo à visão sistêmica da temática ambiental, ao pensamento crítico-reflexivo, ao reconhecimento da diversidade socioambiental, à reflexão das desigualdades e à justiça ambiental, bem como ao uso das diferentes linguagens para a socialização e o diálogo de saberes. Ainda, como dever, tanto o planejamento curricular quanto a gestão precisam contribuir para o reconhecimento da importância da contextualização da realidade local-global, para a revisão de práticas fragmentadas, à promoção do cuidado com as diversas formas de vida, à valorização da multiculturalidade, e à construção da cidadania ambiental.

Considerando o exposto, os Princípios da AC emergiram da leitura do Art. 17 das DCNEA, pelo fato deste se referir ao planejamento curricular e à gestão da instituição. Para isso, foram realizadas as etapas da Análise de Conteúdo (BARDIN, 2011) do referido Artigo, donde as leituras realizadas acerca do processo de AC contribuíram para as interpretações das unidades de análise e definição dos Princípios. A partir deste processo analítico, os Princípios considerados a priori, necessários à potencialização e à institucionalização da $A C$, integrando a EA transversal, interdisciplinar e sistematicamente nos currículos são: 1) Sensibilização estético-ambiental; 2) Complexidade bioecossistêmica; 3) Globalização e Pertencimento ao lugar; 4) Sustentabilidade; 5) Justiça socioambiental; 6) Mudanças do Clima; 7) Pensamento crítico-reflexivo; e 8) Ética e Ecocidadania. 


\section{Princípios da Ambientalização Curricular: breves tessituras}

Aqui, serão tecidas considerações breves acerca dos oito Princípios explanados anteriormente. Ressalta-se que os mesmos precisam ser vistos e operacionalizados em plena simbiose, ciclicamente, e não como um processo linear e/ou isolado.

\section{Sensibilização estético-ambiental}

Falar de estética e de sensibilização são imprescindíveis para o que 0 processo de AC se firme no âmbito educacional. Isto porque o "sensível não é mais um fator secundário na construção da realidade social, [...] não é apenas um momento que se poderia ou deveria superar. [...] É preciso considerá-lo como elemento central no ato de conhecimento" (MAFFESOLI, 1998, p. 188). Nesse sentido, as IES se apresentam como um importante centro à sensibilização e à ressignificação de valores, percepções, conceitos, e práticas sociais, principalmente na organização e na valorização dos saberes com o intuito de aproximar-se das situações socioambientais da sociedade.

Segundo Marin (2006, p. 279), "a palavra estética deriva de aisthesis que significa sentir, sendo a raiz grega aisth, sentir com os sentidos". Esses sentidos a partir do sentir, vêm sendo incapacitados de emergirem nas percepções e ações dos sujeitos, e um dos motivos para isso acontecer, se direciona à "modernidade, especialmente após a eclosão do iluminismo, que veio primando por desenraizar o ser humano não só de sua comunidade local como de seu próprio corpo, em prol de um pensamento abstrato e genérico" (DUARTE JR, 2006, p. 173). Tal desacoplamento corporal, mecaniza os indivíduos a seguir uma marcha contra o tempo e os afazeres cotidianos, sem a possibilidade de experienciar os fenômenos na sua complexidade e na sua totalidade.

Logo, a AC precisa promover uma estimulação da (re)conexão dos seres humanos à natureza, do olhar atento à diversidade dos seres vivos, das diferentes culturas locais, da tradição oral, entre outras, potencializando a percepção sensível do meio ambiente e suas relações (BRASIL, 2012). Assim, integrar a estética nos currículos, é construir junto aos sujeitos aprendentes, 
valores emancipatórios que retomem a capacidade de enxergar o mundo na sua totalidade e agir a favor de sua sustentabilidade. "Quem vivencia o fenômeno da experiência estética tem diante de si um mundo muito mais amplo e flexível que aquele desenhado pelas sociedades de consumo" (MARIN; OLIVEIRA, 2005, p. 209).

Logo, integrar nos currículos uma abordagem de uma EA "conectada com os sentidos e os valores do ser-humano, baseados em concepções individuais e coletivas, vivenciadas e construídas durante a história de vida de cada um" (MOTA, 2016, p. 3), se volta ao início de uma possível mudança paradigmática. Tal mudança emerge para romper com o jeito moderno de ver, existir e conviver no mundo, pois visa uma (re)transformação de comportamentos e um (re)aprender a perceber os acontecimentos do cotidiano em prol à uma vida planetária de qualidade.

\section{Complexidade bioecossistêmica}

A compreensão de processos ecológicos vitais, influências políticas, sociais, econômicas, psicológicas, dentre outras, na relação entre sociedade, meio ambiente, natureza, cultura, ciência e tecnologia (BRASIL, 2012), é mencionada por Odum e Odum (2012), quando apresentaram a Teoria Geral dos Sistemas. Tal teoria tem como objetivo analisar a natureza dos sistemas e a inter-relação entre suas partes, assim como a interação entre eles em diferentes lugares, e ainda, as suas leis fundamentais. Logo, os autores defendem a ideia de que é preciso compreender "[...] a visão do todo e chegar ao particular, [...] para que se possa entender seu funcionamento e analisar suas perspectivas" (ODUM; ODUM, 2012, p. 21). Assim, o fenômeno como um todo, transcende a soma das partes, pois é preciso considerar as múltiplas relações que se estabelecem nas suas articulações.

Nesse aspecto, tendo os seres humanos como agentes constituintes do meio ambiente e integrados nos processos cíclicos naturais, se faz necessária a compreensão de interdependência entre esses fenômenos ecológicos sistemáticos, tendo o termo ecológico visto no seu sentido mais amplo que o usual (CAPRA, 2006). No entanto, isto envolve os pressupostos da complexidade ambiental, tendo-a como a complexidade da vida. Para o desenvolvimento destas discussões, as IES se apresentam como importantes 
centros para discutir tal complexidade. Cada vez mais são necessários debates que estimulem uma reflexão para minimizar os impactos socioambientais a partir de uma visão sistêmica dessas relações que se estabelecem no meio. É aí que o currículo desafia: Como integrar a complexidade e a visão bioecossistêmica nas IES, de modo que estes permitam desenvolver outro olhar sobre a complexidade das interações ser humano-sociedade-natureza?

Uma das possibilidades é trabalhar a EA transversalmente, de modo interdisciplinar. Para Leff (2011, p. 318-19), "a interdisciplinaridade ambiental estabelece a transformação dos paradigmas estabelecidos do conhecimento para internalizar um saber ambiental. [...]", se tornando uma chamada à complexidade, na busca de restabelecer as entre processos de diferentes ordens. A partir deste trabalho interdisciplinar, seria possível estabelecer diálogos sobre questões globais, suas causas e inter-relações em uma perspectiva sistêmica, considerando aspectos relacionados ao meio ambiente. Logo, percebe-se que a interdisciplinaridade e complexidade da visão bioecossistêmica são complementares e dependentes uma da outra na construção do conhecimento. Um currículo que integre essas vertentes, passa a construir abordagens pedagógicas que consideram a interface natural e social, voltadas à problematização da produção exacerbada, do consumo, do trabalho, dentre outras situações que implicam nas inter-relações sociais (BRASIL, 1999).

\section{Globalização e Pertencimento ao Lugar}

$\mathrm{Na}$ atual conjuntura social, situados num contexto de um sistema dominador e mercantilista nas circunstancialidades dessa mundanidade, os sujeitos se tornam cada vez mais incapazes de se auto-afirmarem enquanto indivíduos com uma identidade própria, marcada pelas suas vivências e experiências. Enquanto se encontram sem uma auto-afirmação identitária, buscando no coletivo uma razão para sua corporeidade, existe uma esperança por uma (re)acomodação da existência subjetiva em lugares guardadores de memórias, capazes de fortalecer a essência de cada um. Giddens (2002) caracterizava esses lugares de fuga e de proteção como casulos protetores, que forneceriam segurança, refúgio e aconchego diante uma situação de desencaixe social. 
Com isto, para que o processo de AC se intensifique nas IES, é necessário que os sujeitos que estão no lugar a ser ambientalizado, compreendam esse lugar enquanto mundanidade do cotidiano, necessária para refletir o ser-e-estar no mundo (HEIDEGGER, 2015). Assim, estes sujeitos podem ser capazes de potencializar o sentimento de pertença, tornando as ações significativas e coerentes com os discursos acerca das temáticas socioambientais e curriculares.

Santos (2011, p. 22), apresenta que a globalização "é o ápice do processo de internacionalização do mundo capitalista", e por isso, o pertencimento precisa ser potencializado. No entanto, para discutir o que é este pertencimento, é preciso alavancar uma discussão sobre o que é o lugar, pois como afirma Cousin (2010) a compreensão do lugar busca construir o sentimento de pertencimento, das suas condições naturais ou humanas, e o que acontece no espaço onde se vive. Junto a isto, a autora pontua que "compreender como os processos das relações estão presentes em cada vivência, e como o local e o global estão articulados, se traduzindo em experiências pessoais e coletivas" (2010, p. 95) é fundamental para que haja um compartir do lugar e seus sentidos de pertença nele construídos.

Logo, refletir e compreender sobre o sentido do lugar no mundo contemporâneo não se constitui em uma tarefa simples, haja vista uma vastidão de significados que podem ser atribuídos ao termo. Santos (2008), por exemplo, caracteriza o lugar como uma rede, formada por pontos nodais, resultante da intersecção da verticalidade (formadas por pontos mais distantes, interligados por processos sociais) e da horizontalidade (lugares próximos reunidos por uma continuidade territorial). Ainda para esse autor, cada lugar é, objeto de uma razão local e de uma razão global, convivendo em um movimento dialógico.

Nesse sentido, a integração deste princípio nos currículos vem fortalecer o processo de AC, pois contribui para que se estabeleçam discussões em que os sujeitos compreendam a importância de um pertencimento dialético ao lugar, despertando 0 ato do cuidar, em prol a uma transformação socioambiental (MOTA, 2016), sendo necessário para que a compreensão da importância dos lugares e a influência destes nas ações locais e globais sejam assimiladas pelos sujeitos em formação socioambiental. 


\section{Sustentabilidade}

Pensar na sustentabilidade da vida é pensar na essência do ser que vive, experiencia e comparte das mais diversas circunstancialidades envoltas na mundaneidade socioambiental. Logo, compreendê-la a fundo é necessário para transcender discursos sustentáveis que são impraticáveis e/ou insignificativos para uma vida de qualidade, na sua mais ampla contextualização. Boff (2013), no Prefácio de seu livro Sustentabilidade: o que é - o que não é, afirma que frequentemente ocorre uma falsidade ecológica ao se referir à palavra sustentabilidade. "A maioria daquilo que vem anunciando como sustentável geralmente não o é" (p. 9). Esse mascaramento verde que ilude, persuade e manipula os sujeitos está relacionado à sobreposição do ter sobre o ser, este último colocado em segundo plano na escala de importância socioambiental.

Entretanto, a preocupação com as questões sustentáveis precisa emergir no interior de cada ser, a fim de que a situação seja revertida. Essa necessidade também é ressaltada por Boff (2013, p. 11), quando acentua que, "se olharmos o futuro da humanidade e da Mãe Terra pelos olhos de nossos filhos e netos sentiremos, imediatamente, a necessidade de nos preocuparmos com a sustentabilidade e de criar meios de implementá-la em todos os campos da realidade". Desta forma, pensar a sustentabilidade da pessoa humana é, antes de mais nada, o primeiro passo para pensar as demais sustentabilidades. "O efeito desta sustentabilidade se irradia para além do indivíduo, pois alcança as relações interpessoais e sociais que se mostram mais suaves e produzem o efeito nos outros de sentir-se bem em sua companhia" (BOFF, 2013, p. 162). Isto porque, quando se cuida de si, se preocupa com o outro, sendo esse outro um outro ser, ou a própria natureza (GADAMER, 2008).

Nesse aspecto, os currículos precisam integrar esses valores sustentáveis em sua organização. O estímulo à participação democrática em busca da construção de uma sociedade sustentável, "fundada nos princípios da liberdade, igualdade, solidariedade, democracia, justiça social, responsabilidade e da sustentabilidade" (BRASIL, 1999, p. 2), necessitam acontecer para que tais valores sejam internalizados e traduzidos nas 
intervenções socioambientais. Essas ações podem ser um meio, como mencionou Boff (2013) para trilhar os caminhos sustentáveis. Por isso que a realização de "projetos de intervenção e ações de sustentabilidade na instituição educacional e na comunidade, com foco na prevenção de riscos, na proteção e preservação do meio ambiente e da saúde humana, na construção de sociedades sustentáveis" (BRASIL, 2012, p. 6) se mostra um meio possível para que as IES possam trabalhar este princípio nas suas ações educativas. Estes projetos podem acontecer por meio da extensão universitária por exemplo, fazendo com que tanto a comunidade acadêmica quanto a local se beneficie das ações a serem implementadas acerca das mais diversas dimensões da sustentabilidade.

\section{Justiça Socioambiental}

Tentar imaginar a diversidade existente em Gaia é praticamente algo distante da realidade. Entretanto, mesmo não tendo ciência da multiplicidade de olhares, de vidas, de ecossistemas, de culturas, de gêneros, de etnias, de religião, e de outras tantas que às vezes passam despercebidas às nossas percepções, é necessário que tenhamos o senso crítico-reflexivo que fortaleça o cuidado e o respeito com cada diferença, para que a justiça ambiental prevaleça na luta por igualdade, que infelizmente, está fragilizada.

Diante destas diversidades, voltando o olhar para a biodiversidade de vidas e ecossistemas, Martins e Oliveira (2015, p. 129) mencionaram que esta vem sendo ameaçada, tanto por demandas naturais quanto artificiais. Como exemplo dessas demandas, "está a destruição de habitats naturais; introdução de espécies exóticas e invasoras; exploração excessiva de espécies; caça e pesca sem critérios; tráfico de fauna e flora silvestre; poluição das águas e atmosfera; ampliação desordenada das fronteiras agropecuárias [...]", dentre outras. Assim, percebe-se que a falta de sensibilização humana, de respeito, e de atitudes críticas perante a diversidade de vidas que compartem esse lugar chamado Gaia, é o que mais viola e desafia o "viver juntos em nossa Terra" (SAUVÉ, 2016).

Perante tal fato, se torna relevante que se intensifique nos currículos, a valorização da diversidade de saberes e olhares científicos e populares sobre o meio ambiente, contemplando o diálogo acerca da interação, do cuidado e da 
preservação da casa-de-vida comum. Esses "temas como a conservação da biodiversidade e sua inter-relação com os conceitos de meio ambiente, educação ambiental, sustentabilidade e solidariedade precisam ser tratados" (OLIVEIRA, 2004, p. 61) na busca da sustentabilidade dos sistemas ecológicos dos quais os seres humanos e os demais seres vivos fazem parte.

Outro aspecto referente às diferenças e que ainda carece de concretização nas práticas sociais, é o reconhecimento e respeito à diversidade de religiões, etnias, gênero, pensamentos e visões, culturas, na busca da superação de todas as formas de discriminação. Sato (2002, p. 2) acentuou que, talvez, "o maior desafio da EA se ajusta na busca da alteridade - no respeito aos diferentes. É preciso desejar a transformação social por meio da participação de ideias plurais contidas na essência reflexiva para uma Terra com mais responsabilidade ecológica.".

Posto isso, é relevante estabelecer uma articulação com a $A C$, já que este processo está interligado às questões da ética, da equidade, da luta e justiça ambiental e do cuidado de si, do outro e do meio ambiente, buscando também, dessa forma, integrar os direitos humanos, sociais, econômicos, culturais e ambientais nas formações dos sujeitos enquanto cidadãos e profissionais. É neste viés que se estabelece uma relação com Acselrad (2005, p. 225-6) quando este aborda as questões acerca das lutas por justiça ambiental por parte dos atores sociais que buscam minimizar e/ou terminar com a distribuição desigual dos riscos ambientais, que atinge principalmente os menos favorecidos socialmente.

Para o autor, as lutas por justiça ambiental combinam quatro defesas específicas: dos direitos a ambientes culturalmente específicos (comunidades tradicionais situadas na fronteira da expansão das atividades capitalistas e de mercado); dos direitos a uma proteção ambiental igualitária (contra a segregação sócio-territorial e a desigualdade ambiental); dos direitos de acesso igualitários aos recursos naturais (contra a concentração das terras férteis, das águas e do solo seguro nas mãos dos interesses econômicos); e dos direitos das populações futuras (pela interrupção das formas de transferência dos custos ambientais do desenvolvimento para os mais pobres).

\section{Mudanças do Clima}


Nos últimos anos, as Mudanças do Clima (MC) tornaram-se um tema recorrente na mídia e no cotidiano das pessoas. Segundo Torales (2012, p. 85), "vale destacar que as questões relacionadas com o modelo de desenvolvimento mundial e sua relação com o clima começaram desde a década de 60, desde então, é cada vez mais evidente a preocupação [...]" com esse fenômeno. Na atualidade, segundo Gaudiano et al. (2015), muitos acontecimentos estão agora aos olhos do público, como por exemplo: a escassez e os aumentos dos preços de alimentos prejudicados pelo clima, a migração de grande número de pessoas para áreas urbanas e aos países desenvolvidos, a crescente vulnerabilidade das zonas costeiras por lidar com a intensidade de eventos climáticos extremos, o calor excessivo, entre outros.

Assim, é importante que se tenha a clareza de que a MC é um "problema híbrido" (GAUDIANO et al., 2015, p. 144) e é um desafio à humanidade. Ela envolve "componentes sociais entrelaçados a questões econômicas e políticas, mas também insere o papel intrínseco da educação ambiental na sociedade quando se torna uma dimensão que aponta alternativa frente às evidências latentes de uma crise ambiental" (TOZATO, TORALES CAMPOS, 2015, p. 283). Logo, isto remete a pensar sobre como a formação inicial dos profissionais está integrando conceitos e valores a respeito da temática ambiental e acerca dessa mudança do clima. Esses profissionais precisam estar preparados para compreender o porquê, para quê, com quê e como pensar e agir diante de situações que irão exigir conhecimentos morais, éticos e científicos da esfera socioambiental frente às relações entre as MC e o atual modelo de produção, consumo e organização social, visando à prevenção de desastres ambientais e à proteção das comunidades.

Logo, pressupõe-se que os cursos universitários precisam integrar ao currículo conceitos que trabalhem este princípio, proporcionando debates acerca dos efeitos que causam as MC, dos impactos causados, sobre a vulnerabilidade e resiliência dos atingidos, e da promoção de ações para reverter a situação (BRASIL, 1999). Isto geraria subsídios para que os sujeitos em processo formativo compreendam o fenômeno na sua essência, agindo em prol da superação das injustiças, da desigualdade, e do modo funcionalista da natureza e da própria humanidade. Porém, Guerra, Jacobi et al. (2010, p. 97), afirmam que "do ponto de vista do processo de [...] formação há uma enorme 
lacuna em termos de pesquisa, processos de intervenção e uso de metodologias inovadoras, e mais ainda em debates sobre as MC" e sobre a influência humana nos impactos ambientais.

Essa problematização dos desafios ambientais causados pelas MC, a serem enfrentados pelas atuais e futuras gerações, considerando a interferência do ambiente em uma vida de qualidade (BRASIL, 2012), proporcionaria a construção de "medidas para prever, evitar ou minimizar as causas identificadas desse fenômeno com origem antrópica" (BRASIL, 2009, p. 1) e suas consequências para o ambiente e a qualidade de vida dos seres vivos. É neste viés que o processo de $A C$ está estreitamente interligado à potencialização de estratégias socioambientais vinculadas aos princípios e objetivos da EA, articulando saberes, conhecimentos, ações e valores sociais, éticos e ambientais no contexto educacional. Considerando isto, os currículos necessitam integrar de forma ativa conteúdos e ações que permitam aos acadêmicos uma compreensão dos fenômenos climáticos e seus impactos, relacionando com a capacidade de agir e tomar decisões responsáveis, socialmente e ambientalmente, em sua futura atividade profissional.

\section{Pensamento crítico-reflexivo}

Refletir criticamente tem se tornado uma tarefa árdua em uma sociedade cada vez mais acomodada e manipulada por interesses de terceiros. Quando se remete ao pensamento crítico-reflexivo socioambiental, as preocupações se tornam mais preocupantes e urgem por ações que transformem o modo de sere-estar no mundo (HEIDEGGER, 2015), e não apenas nos adaptem às situações que nos impõem. Essa falta de cuidado com o meio em que se convive e se estabelece inter-relações é fruto da ciência moderna, cujo caráter fragmentador e dualista se sobrepõe ao coletivo e ao sistêmico. Conforme Grün (2012, p. 36), "os seres humanos retiram-se da natureza. Eles olham a natureza como quem olha uma fotografia. A natureza e a cultura passam a ser duas coisas muito distintas".

Logo, considera-se que o pensamento crítico-reflexivo precisa ser compreendido para além dos discursos conscientizadores. Isto porque o viés crítico da EA não visa conscientizar as pessoas, como a maioria diz, reproduzindo um discurso sem fundamentação crítica da significação política 
da palavra. O mundo social não funciona somente em termos de consciência, mas também de práticas (SATO, 2002). Por isso, o pensamento críticoreflexivo precisa estar voltado para ações socioambientais que tenham a intencionalidade de transformar o lugar e toda comunidade de vida planetária. Esse pensar pode ser impulsionado por meio de "estudos filosóficos, científicos, econômicos, políticos e históricos, na ótica da sustentabilidade, valorizando a participação, a cooperação e a ética" (BRASIL, 2012, p. 5).

Não é à toa que muito tem se temido e privado esse pensar. Não por parte das IES, mas por sistemas que estão acima delas. Isto porque a criticidade e a reflexão são ferramentas potentes à ressignificação paradigmática a que o atual sistema está interligado. Um modelo social dominador e regado por interesses que correspondem ao bem de uma pequena parte da população. Um modo de ter e viver que exclui, oprime e acorrenta as pessoas sem que percebam que estão sendo amordaçadas. Transformar esses modelos insustentáveis de vida é uma tarefa a longo prazo. Se a educação for vista como a esperança da mudança social, e acredita-se que ainda é (por mais que se tenha tentado mudar isso), necessita-se pensar as formações dos futuros educadores ambientais como agentes instigadores desse horizonte do pensar e agir crítico-reflexivo. Desde a formação inicial, o estímulo de debates crítico-reflexivos acerca das realidades locais, para que práticas ambientais possam emergir dos sujeitos a fim de transformar o lugar em que vivem, em prol à melhoria do meio ambiente (BRASIL, 2014) precisa estar presente o tempo todo nas teorias e práticas curriculares.

Ou seja, o pensamento crítico-reflexivo precisa ser construído no coletivo, em rede, considerando que "as pessoas se constituem em relação com o mundo em que vivem com os outros e pelo qual são responsáveis juntamente com os outros. [...]" (CARVALHO, 2004, p. 20). É um processo de responsabilidade e de alteridade, de competência para agir ambientalmente e se autotransformar, de pensar nos "desafios a serem enfrentados pelas atuais e futuras gerações, nas dimensões locais, regionais, nacionais e globais" (BRASIL, 2012, p. 5) e de buscar intervenções que os minimizem/solucionem. É uma luta coletiva, política, participativa e democrática. É um ato de amor.

\section{Ética e Ecocidadania}


A ideia de trazer a ecocidadania como parte integrante deste princípio da AC, parte dos pressupostos de Sauvé (2016, p. 296-7), a qual menciona que a "A ecocidadania vai para além do ecocivismo, que se limita à adoção de comportamentos individuais em função de uma moral social. Consiste em desenvolver uma cidadania consciente das linhas estreitas entre sociedade e natureza".

$\mathrm{Na}$ busca dessas inovações ecossociais, os sujeitos que perpassam pelo processo de formação ecocidadã, compreendem e refletem em suas práticas sociais o respeito e a equidade pelas diversidades que compõem a sociedade. Ao ver a união dos povos como uma potência à abertura de horizontes da compreensão do sentido da existência, a utopia da mudança social passa a não ser tão abstrata quanto era ao ser almejada, mas encontra resquícios de que o individualismo precisa ser vencido. Nesse sentido, os currículos necessitam promover o fortalecimento da cidadania e o respeito aos direitos humanos, valendo-se de estratégias de participação democrática e da interação cultural, como fundamentos para o futuro da humanidade (TEASS, 1992).

No entanto, sabe-se que essa ética das relações emerge em momentos de confusão de valores e de sentidos. Imersos em uma conjuntura social que dispõe de multiplicidades subjetivas, políticas, econômicas, culturais, dentre outras, interesses individuais quase sempre se sobrepõem ao coletivo. Mesmo que mecanismos reguladores existam no intuito de contribuir para essa dimensão ética e um conviver respeitoso, ainda é preciso que os indivíduos tenham consigo o pensamento de que a ética é um direito e um dever de cada um enquanto cidadão. Hermann (2001, p. 11) apontou que a "a ética se instaura no âmbito dessa ambiguidade, reconhecendo, por um lado, a fragilidade do humano com suas paixões e, por outro, a tentativa permanente de construir normas que regulem a convivência humana para além da particularidade [...]".

Isto leva a pensar a respeito da dimensão ética da EA. Se os sujeitos ainda carecem do sentimento de alteridade para que o respeito ao seu semelhante possa ser exercido na prática, o movimento que se precisa fazer para se colocar no lugar da natureza parece ser impossível. Grün (2012, p. 101), afirma que "não existe uma saída fácil para o problema ético da 
educação ambiental. Muito menos uma saída unilateral ou unidirecional. Mas existem caminhos capazes de apontar perspectivas [...]" para se pensar" alternativas para fortalecer esse sentido de pertença e cuidado.

Colaborando para isto, os processos educativos precisam incorporar em seus currículos aspectos que unam ética, ecocidadania e a temática ambiental na sua essência, na busca de um repensar a existência no mundo. Questões como o desenvolvimento de uma consciência ética sobre as formas de vida na busca do respeito a seus ciclos vitais (TEASS, 1992); o fortalecimento de valores em prol à conservação do meio ambiente, que é um bem comum do povo (BRASIL, 1999); e o "incentivo à participação individual e coletiva, permanente e responsável, na preservação do equilíbrio do meio ambiente, entendendo-se a defesa da qualidade ambiental como um valor inseparável do exercício da cidadania" (BRASIL, 1999, p. 2); precisam estar presentes na formação dos sujeitos.

\section{Considerações Emergentes}

Saiu o Semeador a semear. Semeou o dia todo e a noite o apanhou ainda com as mãos cheias de sementes. (CORALINA, 2001)

E é nesse processo de semeaduras e colheitas que se vivencia neste momento. Muito já foi semeado para que fosse possível chegar nesse ponto, mas muitas sementes hão de ser lançadas ainda para que a safra seja mais farta. Nesse processo de plantio, os grãos vieram dos mais diversos semeadores, de campos diferentes, de vivências singulares, e de experiências únicas. Logo, por mais que pareça, às vezes, que os percursos são solitários, há sempre um coletivo que colabora para que seja possível o brotar de um acontecimento.

Que essa semeadura coletiva dos Princípios da AC possa fazer com que brotem os horizontes da compreensão da complexidade e da visão bieoecossistêmica da EA, fazendo com que os valores e sentidos emerjam e sejam internalizados pelos sujeitos a partir da estética e da sensibilização ambiental. A partir disso, que o sentimento de pertença aos lugares e a visão alargada da globalização possa fazer parte do perceber crítico e reflexivo, permitindo que haja o fortalecimento da responsabilidade e do respeito para com as diversidades planetárias, ascendendo a luta pela justiça ambiental. Que 
essa luta por justiça, possa atingir positivamente os marginalizados pela sociedade, marcados pela desigualdade social e pelos impactos das Mudanças do Clima que, inevitavelmente, têm sua força maior sobre os mais necessitados. Que o pensar reflexivo-crítico também seja utilizado para buscar mudanças inovadoras, na busca da qualidade de vida de Gaia, e na (re)estruturação da união dos povos. Que tudo isso seja feito com ética, na formação contínua e permanente da ecocidadania.

\section{Referências}

ACSELRAD, Henri. Justiça Ambiental: Narrativas de Resistência ao Risco Social Adquirido. In: Encontros e Caminhos: Formação de Educadoras(es) Ambientais e Coletivos Educadores. Brasília: MMA, 2005.

BARDIN, Laurence. Análise de Conteúdo. 6 ed. São Paulo: Edições 70, 2011.

BOFF, Leonardo. Sustentabilidade - O que é, o que não é. 2 ed. Petrópolis: Vozes, 2013.

BRASIL. Ministério da Educação. Diretrizes Curriculares Nacionais para a Educação Ambiental. Brasília: Ministério da Educação /Conselho Nacional de Educação, 2012.

BRASIL. Ministério da Educação. Lei no 9.795, de 27 de abril de 1999. Dispõe sobre a educação ambiental, institui a Política Nacional de Educação Ambiental - PNEA e dá outras providências. Brasília, DF: Brasília, 1999.

BRASIL. Ministério da Educação. Programa Nacional de Educação Ambiental - ProNEA. Brasília: Coordenação Geral de Educação Ambiental. 3.ed. Ministério do Meio Ambiente, 2014.

BRASIL. Ministério do Meio Ambiente. Lei no 12.187, de 29 de dezembro de 2009. Institui a Política Nacional sobre Mudança do Clima - PNMC e dá outras providências. Brasília, DF: 2009.

CAPRA, Fritjof. A Teia da Vida: uma nova compreensão científica dos sistemas vivos. 8 ed. São Paulo: Cultrix, 2006.

CARVALHO, Isabel de Moura. Educação Ambiental Crítica: nomes e endereçamentos da educação. In: LAYRARGUES, Philippe Pomier (coord.). Identidades da educação ambiental brasileira. Brasília: Ministério do Meio Ambiente, 2004. p. 13-24.

CORALINA, Cora. Mascarados. Folha de S. Paulo. Folha ilustrada, 4 jun. 2001. Disponível em: http://acervo.folha.uol.com.br/fsp/2001/06/04. Acesso em: 02 jul. 2017. 
COUSIN, Claudia da Silva. Pertencer ao navegar, agir e narrar: a formação de educadores ambientais. 2010. 207 f. Tese - Doutorado em Educação Ambiental, FURG, Rio Grande, 2010.

DUARTE JR, João Francisco. O sentido dos sentidos: a educação (do) sensível. Curitiba/PR - Criar Edições, 2006.

GADAMER, Hans-Georg. Verdade e Método: Traços fundamentais de uma hermenêutica filosófica. 10 ed. Petrópolis: Vozes, 2008.

GAUDIANO, Edgar Javier González et al. Novos desafios para a educação ambiental: vulnerabilidade e resiliência social em face dos estragos da mudança climática. REMEA., v. 32, n. 2, p. 143-158, 2015.

GIDDENS, Anthony. Modernidade e identidade. 1 ed. Rio de Janeiro: J. Zahar, 2002.

GRÜN, Mauro. Ética e Educação Ambiental: a conexão necessária. 14 ed. Campinas: Papirus, 2012.

GUERRA, Antonio Fernando Silveira; JACOBI, Pedro Roberto et al. Mudanças climáticas, mudanças globais: desafios para a Educação. REMEA. 2010, p. 88105.

HEIDEGGER, Martin. Ser e tempo. 10 ed. Vozes: Petrópolis, 2015.

HERMANN, Nadja. Pluralidade e ética em Educação. Rio de Janeiro: DP\&A, 2001.

JUNYENT, Mercè; GELI, Anna Maria; ARBAT, Eva (Orgs.). Ambientalización Curricular de los Estudios Superiores. Proceso de Caracterización de la Ambientalización Curricular de los Estudios Superiores. Girona: Universitat de Girona - Red ACES, 2003. v. 2, p. 15-32.

LEFF, Enrique. Complexidade, interdisciplinaridade e saber ambiental. Olhar de professor, v. 14, n. 2. p. 309-335, 2011.

MAFFESOLI, Michel. Elogio da razão sensível. Rio de Janeiro: Vozes, 1998.

MARIN, Andreia Aparecida. A Educação Ambiental nos caminhos da sensibilidade estética. Inter-Ação: Rev. Fac. Educ. UFG, v. 31, n. 2, p. 277290, jul./dez. 2006.

MARIN, Andreia Aparecida; OLIVEIRA, Luiz Cláudio. A experiência estética em Dufrenne e Quintás e a percepção de natureza: para uma Educação Ambiental com bases fenomenológicas. REMEA, v. 15, n. 1, out. 2012.

MARTINS, Camila; OLIVEIRA, Haydée Torres de. Biodiversidade no contexto escolar: concepções e práticas em uma perspectiva de Educação Ambiental Crítica. RevBEA, São Paulo, v. 10, n. 1, p. 127-145, 2015. 
MOTA, Junior Cesar. A Educação Ambiental Estética como uma ferramenta à (re)significação do ser-sensível. In: IV Seminário Interfaces Pedagógicas, 2016, Rio Grande. Anais....Pluscom, 2016. v. 4. p. 38-41. Disponível em: http://media.wix.com/ugd/c76807 e4d91a75df3a44b39b08233550658a4d.pdf.

ODUM, Howard; ODUM, Elizabeth. 0 declínio próspero: princípios e políticas. Petrópolis: Vozes. 2012.

OLIVEIRA, H.T. (Bio)Diversidade, sustentabilidade e solidariedade: conceitos centrais para a formação de educadores ambientais. In: IX SEMINÁRIO APEC, 2004. Anais... Barcelona: APEC, 2004. p. 57-62.

SANTOS, Milton. A Natureza do Espaço. Técnica e Tempo. Razão e Emoção. 4 ed. São Paulo: Universidade Federal de São Paulo, 2008.

SANTOS, Milton. Por uma outra globalização: do pensamento único à consciência universal. 20. ed. Rio de Janeiro: Record, 2011.

SATO, Michèle. Debatendo os desafios da Educação Ambiental. Ambiente \& Educação, Rio Grande, v. 5, n.1, 2002, p. 14-33.

SAUVÉ, Lucie. Viver juntos em nossa Terra: desafios contemporâneos da Educação Ambiental. Contrapontos, Itajaí, v. 16, n. 2, p. 288-299, ago. 2016.

TEASS. Tratado de educação ambiental para sociedades sustentáveis e responsabilidade global. 1992.

TORALES, Marília Andrade. Formação de professores para novos contextos: a ação educativa escolar frente às mudanças climáticas. In: Seminário Internacional. Anais... São Tomé e Príncipe, 2012, p. 84-87.

TOZATO, Mariana de Oliveira; TORALES CAMPOS, Marília Andrade. Educação ambiental e mudanças climáticas: uma pesquisa exploratória no contexto brasileiro. Ambientalmente Sustentable, v. 2, n. 20, p. 281-296. 